\title{
The association between isolated oligohydramnios at term and pregnancy outcome and perinatal outcome in case of isolated oligohydramnosis: a retrospective analysis
}

\author{
Vijay M. Kansara, Kunal D. Kadakar*, Akash S. Chikani, Pinal A. Pateliya
}

Department of Obstetrics and Gynecology, GMERS Medical College and Hospital, S. G. Highway, Sola, Ahmedabad, Gujarat, India

Received: 17 November 2021

Accepted: 06 December 2021

*Correspondence:

Dr. Kunal D. Kadakar,

E-mail: kkadakar@gmail.com

Copyright: ( ) the author(s), publisher and licensee Medip Academy. This is an open-access article distributed under the terms of the Creative Commons Attribution Non-Commercial License, which permits unrestricted non-commercial use, distribution, and reproduction in any medium, provided the original work is properly cited.

\begin{abstract}
Background: Current study was carried out to assess the impact of isolated oligohydramnios on perinatal outcomes and mode of delivery.

Methods: A retrospective observational cohort study was conducted at term pregnancy with sonographic finding of isolated oligohydramnios (AFI $<5 \mathrm{~cm}$ ) were recruited for the study. Uterine anomaly and high risk pregnancies were excluded from the study. The mode of delivery and perinatal outcome were compared with control group of pregnancy with normal amniotic fluid (AFI $>5-25 \mathrm{~cm})$.

Results: When compared to the normal AFI, women with oligohydramnios had significantly lower birth weight babies and were delivered at a significantly earlier gestational age. However there was no difference in the APGAR scores at birth and NICU admissions between the two groups. Reactive NST had more chances of good APGAR score at 1 and 5 minute and that lower the AFI more the probability of nonreactive NST and abnormal Doppler. The number of inductions and caesareans done for foetal reasons were significantly higher in the exposed group.

Conclusions: Obstetric and perinatal outcome remains similar in both isolated oligohydramnios with reactive NST as well as in patients with normal amniotic fluid index. Isolated oligohydramnios is not associated with adverse perinatal outcomes. However, it increases the risk for labour induction and caesarean section.
\end{abstract}

Keywords: AFI, Isolated oligohydroamniosis, Perinatal outcome

\section{INTRODUCTION}

The incidence of oligohydramnios at term varies greatly between different studies with a reported incidence of $0.5-5 \%$, depending on the study population, gestational age and the definition of oligohydramnios. ${ }^{1,2}$ Oligohydramnios has been defined as liquor volume less than the 5th percentile for that gestational age single deepest pocket or maximum vertical pocket of less than 2 $\mathrm{cm}$ or Amniotic fluid index (AFI) of less than $5 \mathrm{~cm} .^{2} \mathrm{It}$ affects $2.4 \%$ of pregnancies between $36-40$ weeks and $12 \%$ of pregnancies at 41 weeks or later. Oligohydramnios can be isolated or associated with maternal or fetal conditions such as hypertension, premature rupture of membranes, fetal growth restriction and congenital anomalies. While perinatal outcomes of associated oligohydramnios are related to the underlying condition, the natural history of isolated oligohydramnios is unclear. Several studies have shown association of oligohydramnios with an increased caesarean delivery rate, an increase in non reassuring Fetal heart rate (FHR) pattern and adverse perinatal outcome such as preterm delivery, low birth weight, fetal distress, Meconium passage, low APGAR score, NICU admission. ${ }^{3-6}$ These disorders may result from abnormal fetal or maternal conditions and, conversely, may be responsible for alterations of fetal well-being as well. Since, these 
disorders of liquor amnii has a significant impact on pregnancy and fetus, it prompted us to carry out this study with sincere efforts to evaluate the effect of isolated oligohydramnios on obstetrics and perinatal outcome.

\section{METHODS}

A retrospective cohort study of all singleton pregnancies at term $(37+0$ to 40 weeks $)$ who attempted vaginal delivery in a GMERS medical college and hospital between 1 July 2017 and 30 December 2018 were included in this study. All gravid patients who were being assessed in the obstetrical follow-up clinic in our medical center undergo a sonographic assessment of the amniotic fluid volume as an integral part of fetal assessment during the study period. Eligible women (case) for the study group were those with isolated oligohydramnios [amniotic fluid index (AFI) $<5 \mathrm{~cm}$ ) with following inclusion and exclusion criterias.

\section{Inclusion criteria}

Inclusion criteria for current study were; single live intrauterine gestation with cephalic presentation, 37-40 weeks of gestation, intactmembrane, AFI less than or equal to $5 \mathrm{~cm}$.

\section{Exclusion criteria}

Exclusion criteria for current study were; uterine anomaly; high risk pregnancy, hypertensive disorder of pregnancy diabetes, chronic renal disease/cardiac disease and other medical and surgical ailment, connective tissue disorder, preeclampsia, previous scarred uterus.

\section{Procedure}

During the study period in OBGY ward 50 term pregnancies (case) with isolated oligohydramnios were recorded, which were included in this study. Term pregnancies with normal amniotic fluid (AFI $>5-25 \mathrm{~cm}$ ) were taken as control group.

During the study period in OBGY ward 50 term normal pregnancies; amniotic fluid (AFI $>5-25 \mathrm{~cm}$ ) were recorded, which were included in this study and followed up. The mode of delivery and perinatal outcome were compared with control group of pregnancy. Data was entered into a computer database using Microsoft Excel spreadsheet and statistical analysis was performed. Results were presented as frequencies, percentages and appropriate statistical tests were applied.

\section{Statistical analysis}

Data in continuous variables were presented as mean with standard deviation and ranges. Differences in continuous variables were analyzed with test of significance of difference between two means. categorical data was compared using Chi-Square test or Fisher's Exact test. Statistically significant differences were evaluated using Chi-Square or Fisher's Exact test.

\section{RESULTS}

Total $60.00 \%$ of cases and $92.00 \%$ of controls had normal vaginal delivery whereas $40.00 \%$ of cases and $8.00 \%$ of controls underwent LSCS (Table 1).

Table 1: Correlation of mode of delivery between two groups.

\begin{tabular}{|c|c|c|c|c|c|c|}
\hline \multirow{2}{*}{ Mode of delivery } & \multicolumn{4}{|c|}{ Groups } & \multirow{2}{*}{ Total } & \multirow{2}{*}{ P value } \\
\hline & Case & $\%$ & Control & $\%$ & & \\
\hline Vaginal & 30 & 60.00 & 46 & 92.00 & 76 & \multirow{3}{*}{0.0004} \\
\hline LSCS & 20 & 40.00 & 4 & 8.00 & 24 & \\
\hline Total & 50 & 100.00 & 50 & 100.00 & 100 & \\
\hline
\end{tabular}

Table 2: Correlation of NST and mode of delivery among cases.

\begin{tabular}{|c|c|c|c|c|c|c|}
\hline \multirow{2}{*}{ NST } & \multicolumn{4}{|c|}{ Mode of delivery } & \multirow{2}{*}{ Total } & \multirow{2}{*}{ P value } \\
\hline & Vaginal & $\%$ & LSCS & $\%$ & & \\
\hline Reactive & 24 & 48.00 & 09 & 18.00 & 33 & \multirow{3}{*}{0.0241} \\
\hline Non reactive & 06 & 12.00 & 11 & 22.00 & 17 & \\
\hline Total & 30 & 60.00 & 20 & 40.00 & 50 & \\
\hline
\end{tabular}

Data suggests that difference in cesarean section rate was significant, $\mathrm{p}=0.0004$. Correlation of NST and mode of delivery among cases is depicted in (Table 2). A total of 33 cases were reactive NST.

Out of which 09 (18\%) underwent LSCS and 24 (48\%) had vaginal delivery. A total of 17 cases were Non reactive NST. Out of which 11
(22\%) underwent LSCS and 06 (12\%) had vaginal delivery. Thus, indicating that non reactive NST had higher chances of undergoing LSCS. This result was found statistically significant $(\mathrm{p}=0.0241)$. Nature of amniotic fluid in both the groups is shown in (Table 3). $64 \%$ of cases and $82 \%$ of controls had clear liquor whereas $36 \%$ of cases and $18 \%$ controls had meconium stained liquor. 
Table 3: Nature of amniotic fluid.

\begin{tabular}{|c|c|c|c|c|c|c|}
\hline \multirow{2}{*}{ Liquor } & \multicolumn{4}{|c|}{ Groups } & \multirow{2}{*}{ Total } & \multirow{2}{*}{$P$ value } \\
\hline & Case & $\%$ & Control & $\%$ & & \\
\hline Clear & 32 & 64.00 & 41 & 82.00 & 73 & \multirow{3}{*}{0.070} \\
\hline MSL & 18 & 36.00 & 9 & 18.00 & 27 & \\
\hline Total & 50 & 100.00 & 50 & 100.00 & 100 & \\
\hline
\end{tabular}

Table 4: Correlation of AFI and mode of delivery among cases.

\begin{tabular}{|llllll|l|}
\hline AFI $(\mathrm{cm})$ & Groups & & & & Total & P value \\
\cline { 1 - 7 } & Vaginal & \% & LSCS & \% & 24 & \\
\cline { 1 - 6 } & 10 & 20.00 & 14 & 28.00 & 24 & 0.024 \\
\hline Total & 20 & 40.00 & 06 & 12.00 & 26 & \\
\hline
\end{tabular}

Table 5: Correlation of mean AFI with Doppler and mean APGAR score at 1 and 5 minutes and NST with Doppler among cases.

\begin{tabular}{|llll|}
\hline NST with Doppler group & Mean AFI & $\begin{array}{l}\text { Mean APGAR score at } \\
1 \text { minute }\end{array}$ & $\begin{array}{l}\text { Mean APGAR score at } \\
\mathbf{5} \text { minutes }\end{array}$ \\
\hline Reactive NST & 3.39 & 8.06 & 9.63 \\
\hline Non reactive NST+normal Doppler & 1.81 & 6.72 & 8.63 \\
\hline Non reactive NST+abnormal Doppler & 0.66 & 5.33 & 7.33 \\
\hline
\end{tabular}

Table 6: Requirement of NICU admission.

\begin{tabular}{|c|c|c|c|c|c|c|}
\hline \multirow{2}{*}{$\begin{array}{l}\text { Requirement of NICU } \\
\text { admission }\end{array}$} & \multicolumn{4}{|c|}{ Groups } & \multirow{2}{*}{ Total } & \multirow{2}{*}{$P$ value } \\
\hline & Case & $\%$ & Control & $\%$ & & \\
\hline Yes & 12 & 24.00 & 5 & 10.00 & 17 & \multirow{3}{*}{0.110} \\
\hline No & 38 & 76.00 & 45 & 90.00 & 83 & \\
\hline Total & 50 & 100.00 & 50 & 100.00 & 100 & \\
\hline
\end{tabular}

This result was found statistically non significant $(p=0.070)$. Correlation of AFI and mode of delivery among cases is shown in (Table 4). Out of 20 cases undergoing LSCS, maximum cases were seen in women with $\mathrm{AFI}=02 \mathrm{~cm}$. In cases with $\mathrm{AFI}=0$, all women underwent LSCS. None of the women with AFI=5 cm underwent LSCS. Out of 30 cases of successful vaginal delivery, maximum cases were seen in women with AFI=3-5 cm. Thus, indicating that lower the AFI more the probability of undergoing LSCS. This result was found statistically significant $(\mathrm{p}=0.024)$. Correlation of mean APGAR score at 1 and $5 \mathrm{~min}$ and NST with Doppler among cases. Mean APGAR score at 1 and 5 minute in reactive NST group was 8.06 and 9.63 respectively. Mean APGAR score at 1 and 5 minute in nonreactive NST with normal Doppler group was 6.72 and 8.63 respectively.

Mean Apgar score at 1 and 5 minute in nonreactive NST with abnormal Doppler group was 5.33 and 7.33 respectively. Thus, indicating that reactive NST had more chances of good APGAR score at 1 and 5 minute and that lower the AFI more the probability of nonreactive NST and abnormal Doppler. Requirement of NICU admission in both groups is shown in (Table 6). $12(24.00 \%)$ newborn in cases and 5 $(10.00 \%)$ newborn in controls required NICU admission. This result was found statistically non significant $(\mathrm{p}=0.110)$.

\section{DISCUSSION}

Mathuriya et al reported that $35 \%$ of women in case group had undergone LSCS in comparison to $10 \%$ of control group. The $\mathrm{p}$ value was 0.0004 (significant). Elective cesarean section $48.5 \%$ was the most common indication for LSCS in cases, while other indications were fetal distress, MSL, NPOL and failure of induction. Sowmya et al reported incidence of LSCS was $68 \%$ in cases compared to $28 \%$ in control group. It was significant statistically $(\mathrm{p}=0.0001)$. In patients with isolated oligohydramnios, $50 \%$ underwent cesarean section for fetal distress. ${ }^{8}$ In a study by Kavitha et al incidence of LSCS was $56 \%$ in cases and $08 \%$ in control group as compared to (62\% vs. $24 \%)$ and (64\% vs. $22 \%)$ in Padmini et al and Chate et al study respectively $(\mathrm{p}<0.01)^{9,10}$

In a study by Purvi et al higher incidence of LSCS was reported, $81.25 \%$ in cases and $26.56 \%$ in control group; 
there was a higher incidence of LSCS in comparison to our study. In this study incidence of LSCS was $40 \%$ in case group and $08 \%$ in control group. Rate of LSCS was higher in isolated oligohydramnios group and it was statistically significant $(\mathrm{p}=0.004)$. Most common indication of LSCS reported in present study was fetal distress in $15(30 \%)$ cases and $4(8 \%)$ in control group. ${ }^{7}$ Jagatia et al reported operative morbidity was significantly higher in nonreactive NST (24\%) group than NST reactive (18\%) group. Vaginal delivery was significantly higher in NST reactive $(50 \%)$ group than non-reactive NST $(08 \%)$ group $(\mathrm{p}=0.003)$. In the present study it was observed that LSCS was significantly higher in nonreactive NST (22\%) group than NST reactive (18\%) group. Vaginal delivery was significantly higher in NST reactive $(48 \%)$ group than non-reactive NST $(12 \%)$ group $(\mathrm{p}=0.0241) .^{5}$

Purvi et al investigated the relationship of isolated oligohydramnios at term and meconium stained liquor and they found that occurrence of meconium stained liquor in the case group was $51.25 \%$ while it was $35 \%$ in the control group, and Found out that occurrence of meconium staining of liquor was affected by presence of isolated oligohydramnios at term $(\mathrm{p}=0.009) .{ }^{7}$ Similarly in 2016 Padmini et al found significantly increased incidence meconium stained liquor in study group. Sowmya et al investigated that occurrence of meconium stained liquor in the cases was $32 \%$ while it was $18 \%$ in the control group but it was statistically not significant $(p=0.165)$. Similarly Kavitha et al found that occurrence of meconium stained liquor in cases and control group was $22 \%$ and $10 \%$ respectively $(p>0.05) .{ }^{8,9}$ In comparison to that, in the present study occurrence of meconium stained liquor in cases and control group was $36 \%$ and $18 \%$ respectively with $\mathrm{p}=0.07$, which is statistically not significant. Kavitha et al observed that APGAR score $<7$ at $1 \mathrm{~min}$ and 5 min was $24 \%$ and $8 \%$ in cases respectively while $12 \%$ and $4 \%$ in control group respectively. ${ }^{9}$ Padmini CP et al reported APGAR score $<7$ at 5 min was $8 \%$ in cases and $4 \%$ in control group which is comparable to study conducted by Kavitha et al. Chate et al reported APGAR score $<7$ at 5 min was $16 \%$ in cases and $6 \%$ in control group; there was a higher incidence of low APGAR score in comparison to our study. ${ }^{9,10}$ In the present study, it was observed that APGAR score $<7$ at $1 \mathrm{~min}$ and 5 min was $24 \%$ and $4 \%$ in cases respectively while it was $4 \%$ and $0 \%$ in control group respectively, and concluded that Mean APGAR score at 1 and 5 minute in reactive NST group was 8.06 and 9.63 respectively while in nonreactive NST with abnormal Doppler group was 5.33 and 7.33 respectively. Purvi et al and Sowmya et al reported higher rate of NICU admission, but it was not significant statistically ( $p$ value >0.05). ${ }^{7,8}$ Padmini et al and Chate et al reported higher rate of NICU admission; they have shown a higher incidence of NICU admission in comparison to our study. $(\mathrm{p}=0.0007) .{ }^{10,11}$ Kavitha et al reported $18 \%$ of babies among cases and $4 \%$ of babies among controls went to NICU; they have shown a lower incidence of NICU admission in comparison to our study. ${ }^{9}$ In the present study, it was observed that neonatal intensive care unit admission was needed in $24 \%$ of newborns in cases and $10 \%$ in the control group, which is statistically not significant with $\mathrm{p}=0.108$. $2(4 \%)$ newborn required assisted ventilation while $10(20 \%)$ required only bag and mask ventilation in case group. No newborn required assisted ventilation in the control group.

\section{Limitations}

Current study was a unicentric study. Multicentric study should be carried out to validate the findings of our study. Sample size in our study is small. The study should be conducted with large sample size to see that observation is reproducible. The study was restricted to gestational age of 40 weeks. The study can be further conducted with extension of gestational age.

\section{CONCLUSION}

Obstetric and perinatal outcome remains similar in both isolated oligohydramnios with reactive NST as well as in patients with normal amniotic fluid index. Isolated oligohydramnios is not an indication of elective caesarean section or induction of labour before 40 weeks of gestation unless it is associated with non-reactive NST with abnormal Doppler. Isolated oligohydramnios is not associated with adverse perinatal outcomes. However, it increases the risk for labour induction and Caesarean section.

Funding: No funding sources

Conflict of interest: None declared

Ethical approval: The study was approved by the Institutional Ethics Committee

\section{REFERENCES}

1. Hill LM, Breckle R, Wolfgram KR, O’Brien PC. Oligohydramnios: ultrasonically detected incidence and subsequent fetal outcome. Am J Obstet Gynecol. 1983;147:407-10

2. Mercer LJ, Brown LG, Petres RE, Messer RH. A survey of pregnancies complicated by decreased amniotic fluid. Am J Obstet Gynecol. 1984;149:35561.

3. Casey BM, McIntire DD, Bloom SL, Lucas MJ, Santos R, Twickler DM, et al. Pregnancy outcomes after antepartum diagnosis of oligohydramnios at or beyond 34 weeks' gestation. Am J Obstet Gynecol. 2000;182(4):909-12

4. Chauhan SP, Sanderson M, Hendrix NW, Magann EF, Devoe LD. Perinatal outcome and amniotic fluid index in the antepartum and intrapartum periods: a meta-analysis. Am J Obstet Gynecol. 1999;181(6): 1473-8.

5. Jagatia K. Maternal and fetal outcome in oligohydramnios. Int J Med Sci Public Health. 2013; 2(3):724-7. 
6. Ghosh G, Marsal K, Gudmundsson S. Amniotic fluid index in low-risk pregnancy as an admission test to the labor ward. Acta Obstet Gynecol Scand. 2008;81: 852-5.

7. Patel PK, Pitre DS, Gupta H. Pregnancy outcome in isolated oligohydramnios at term. Neonatal J Commu Med. 2015:6(2):217

8. Varghese SKB, Borkar UY. Effect of isolated oligohydramnios in otherwise normal term pregnancy. Int J Biomed Res. 2014;5(2):98-101.

9. Kavitha G. Pregnancy outcome in isolated oligohydramnios at or beyond 34 weeks of gestation. Int J Cur Res Rev. 2015;7(2):62-8.

10. Padmini CP, Chaitra R, Indra N. A prospective study of effect of amniotic fluid index less than 5 at term on perinatal outcome. Int J Reprod Contracept Obstet Gynecol. 2016;5(6):1732-5.

11. Chate P, Khatri M. Pregnancy outcome after diagnosis of oligohydramnios at term. Int $\mathbf{J}$ Reprod Contracept Obstet Gynecol. 2013;2(1):23-6.

Cite this article as: Kansara VM, Kadakar KD, Chikani AS, Pateliya PA. The association between isolated oligohydramnios at term and pregnancy outcome and perinatal outcome in case of isolated oligohydramnosis: a retrospective analysis Int J Reprod Contracept Obstet Gynecol2022;11:13640. 